\title{
Total exchangeable potassium in response to amiloride
}

\author{
V. R. PeARCe \\ M.B., M.R.C.P. \\ D. G. BEEVERS \\ M.B., M.R.C.P.
}

\author{
A. C. AntClifF \\ M.B., B.S. \\ M. HAMILTON \\ M.D., F.R.C.P.
}

\section{Chelmsford Group of Hospitals}

\begin{abstract}
Summary
The use of amiloride is described in twenty-four hypertensive patients who became hypokalaemic as a result of thiazide diuretic therapy in spite of oral potassium supplements. Amiloride caused a significant rise in exchangeable potassium, exchangeable potassium/kg body weight, and plasma potassium, together with a significant fall in plasma total carbon dioxide, body weight, systolic and diastolic blood pressures.

These results suggest that amiloride has a useful role in this type of patient.
\end{abstract}

\section{Introduction}

Most studies of potassium changes in response to diuretics in hypertensive patients have failed to demonstrate a large total potassium deficit (Talso and Carballo, 1960; Graybiel and Sode, 1961; Gifford et al., 1961 ; Anderson et al., 1971; Wilkinson et al., 1975; Leemhuis, van Damme and Stuyvenberg, 1976), and the need for potassium supplements has been questioned (Healy et al., 1970; Wilkinson et al., 1975).

Although an increased potassium loss has been shown in short-term experiments by studies of metabolic balance (Maronde, Milgram and Dickey, 1969), exchangeable potassium (Gifford et al., 1961) and whole body potassium (Leemhuis et al., 1976), the increased excretion appears not to persist, and the initial loss is partly reversed or compensated later on.

The plasma or serum potassium tends to remain lower than in the period before diuretics were administered (Beevers, Hamilton and Harpur, 1971), however, and it has been concluded that part of this effect, at least, is the result of redistribution of potassium between the intra- and extra-cellular body compartments (Leemhuis et al., 1976). Talso and Carballo (1960) suggest that this may result from the hypochloraemic alkalosis that usually occurs during diuretic treatment. This has not been confirmed by others.

Despite the frequent occurrence of hypokalaemia in patients taking thiazide diuretics for long periods, subjective symptoms are rare (Beevers et al., 1971). In spite of this, it is felt desirable to minimize potassium depletion which may have serious consequences in the event of a potassium-losing state or the need for digitalis.

Triamterene has been found ineffective in reversing potassium depletion (McKenna et al., 1971). Spironolactone has been shown to reduce the potassium loss to a considerable extent, but the use of this agent is limited by a high incidence of side effects, in particular gastric intolerance. Slow-release potassium chloride (Slow-K, Ciba) has been shown to be effective in replacing potassium loss resulting from prolonged thiazide diuretic administration (McKenna et al., 1971). However, the number of patients studied was small and the authors have not found that slow-release potassium chloride in apparently adequate doses always prevents or reverses hypokalaemia and alkalosis (Antcliff et al., 1971).

A solution of potassium chloride was demonstrated as not affecting total body potassium in patients treated with chlorthalidone (Leemhuis et al., 1976).

The present authors have therefore investigated the ability of a 'potassium-sparing' diuretic, amiloride, to reverse the potassium deficit induced in hypertensive patients by long-term thiazide therapy in spite of oral potassium supplements.

\section{Subjects and methods}

Patients were selected on the basis of having developed and sustained a low level of plasma potassium, measured on at least two occasions whilst visiting the out-patient department for routine 
blood pressure checks. The hypokalaemia developed in the course of long-term treatment with thiazide diuretics for hypertension alone, and the blood pressure was satisfactorily controlled throughout the period of assessment, with one exception (see Table 1). Furthermore, the low plasma potassium developed whilst the subjects were receiving at least $32 \mathrm{mmol}$ potassium/day.

The potassium was in the form of slow release potassium chloride (Slow-K, Ciba) in twenty-two cases; as potassium gluconate solution (Katorin, Boots) in one, and as effervescent tablets (Kloref, Cox-continental) in another. The thiazide diuretic was in most cases hydroflumethiazide $100 \mathrm{mg}$ or $200 \mathrm{mg} /$ day, but in two cases was hydrochlorothiazide and bendrofluazide respectively, and in a further two cases was chlorothiazide. Fourteen subjects received no other therapy but in two,

TABLE 1. Exchangeable potassium, plasma potassium, ratio $\mathrm{K}_{\mathrm{e}} / \mathrm{kg}, \mathrm{TCO}_{2}$, Supine $\mathrm{BP}$ and the time at which they were measured after starting amiloride

\begin{tabular}{|c|c|c|c|c|c|c|c|c|}
\hline \multirow[b]{2}{*}{ Subject } & \multirow{2}{*}{$\begin{array}{c}\mathrm{K}_{\mathrm{e}} \\
(\mathrm{mmol})\end{array}$} & \multirow{2}{*}{$\begin{array}{l}\text { Weight } \\
\text { (kg) }\end{array}$} & \multirow{2}{*}{$\begin{array}{c}\text { Ratio } \\
\left(\mathrm{K}_{\mathrm{e}} / \mathbf{k g}\right)\end{array}$} & \multirow{2}{*}{$\underset{(\mathrm{mmol})}{\text { Plasma K }}$} & \multirow[b]{2}{*}{$\mathrm{TCO}_{2}$} & \multicolumn{2}{|c|}{ Supine BP (mmHg) } & \multirow{2}{*}{$\begin{array}{c}\text { Time } \\
\text { (months) }\end{array}$} \\
\hline & & & & & & Syst. & Diastol. & \\
\hline 1 & 1840 & $65 \cdot 20$ & $28 \cdot 22$ & $3 \cdot 1$ & 28 & 140 & 80 & 0 \\
\hline & 1955 & $64 \cdot 15$ & $30 \cdot 48$ & $3 \cdot 8$ & 29 & 120 & 70 & 5 \\
\hline \multirow[t]{2}{*}{2} & 2660 & $66 \cdot 68$ & $39 \cdot 89$ & $3 \cdot 3$ & 31 & 200 & 100 & 0 \\
\hline & 2350 & $66 \cdot 68$ & $35 \cdot 24$ & $3 \cdot 5$ & 31 & 190 & 90 & 5 \\
\hline \multirow[t]{2}{*}{3} & 1965 & $66 \cdot 68$ & $29 \cdot 47$ & $3 \cdot 2$ & 29 & 170 & 90 & 0 \\
\hline & 1904 & $64 \cdot 86$ & $29 \cdot 36$ & $3 \cdot 2$ & 27 & 160 & 90 & 6 \\
\hline \multirow[t]{2}{*}{4} & 2620 & $79 \cdot 38$ & 33.00 & $3 \cdot 1$ & 38 & 180 & 80 & $\mathbf{0}$ \\
\hline & 3170 & 75.97 & $41 \cdot 73$ & $3 \cdot 6$ & 29 & 140 & 85 & 5 \\
\hline \multirow[t]{2}{*}{5} & 2385 & $69 \cdot 62$ & $34 \cdot 26$ & $3 \cdot 3$ & 34 & 140 & 80 & 0 \\
\hline & 2690 & $68 \cdot 71$ & $39 \cdot 15$ & $4 \cdot 0$ & 32 & 120 & 80 & 6 \\
\hline \multirow[t]{2}{*}{6} & 1875 & $49 \cdot 66$ & $37 \cdot 76$ & $3 \cdot 1$ & 33 & 200 & 100 & 0 \\
\hline & 1826 & $48 \cdot 86$ & $37 \cdot 37$ & $3 \cdot 7$ & 31 & 180 & 90 & 6 \\
\hline \multirow[t]{2}{*}{7} & 2700 & $72 \cdot 34$ & $37 \cdot 32$ & 3.0 & 27 & 150 & 90 & 0 \\
\hline & 2275 & $70 \cdot 76$ & $32 \cdot 15$ & 5.0 & 27 & 130 & 80 & 4 \\
\hline \multirow[t]{2}{*}{8} & 2570 & $82 \cdot 55$ & $31 \cdot 13$ & $2 \cdot 5$ & 36 & 160 & 90 & 0 \\
\hline & 3130 & $82 \cdot 32$ & 38.02 & $3 \cdot 2$ & 35 & 160 & 110 & 4 \\
\hline \multirow[t]{2}{*}{9} & 2800 & $82 \cdot 32$ & 34.01 & $3 \cdot 2$ & 34 & 130 & 90 & 0 \\
\hline & 3200 & $80 \cdot 29$ & $39 \cdot 86$ & $3 \cdot 3$ & 28 & 140 & 90 & 6 \\
\hline \multirow[t]{2}{*}{10} & 2880 & 83.92 & $34 \cdot 32$ & $2 \cdot 9$ & 34 & 140 & 90 & 0 \\
\hline & 3260 & $82 \cdot 10$ & $39 \cdot 71$ & $3 \cdot 8$ & 30 & 140 & 85 & 5 \\
\hline \multirow[t]{2}{*}{11} & 1440 & $75 \cdot 97$ & 18.95 & $3 \cdot 8$ & 28 & 210 & 130 & 0 \\
\hline & 1465 & $75 \cdot 51$ & $19 \cdot 40$ & $4 \cdot 3$ & 28 & 170 & 100 & 3 \\
\hline \multirow[t]{2}{*}{12} & 1939 & $60 \cdot 33$ & $32 \cdot 14$ & $2 \cdot 7$ & 29 & 170 & 105 & 0 \\
\hline & 2445 & $60 \cdot 78$ & $40 \cdot 23$ & $3 \cdot 4$ & 29 & 160 & 95 & 6 \\
\hline \multirow[t]{2}{*}{13} & 1530 & $58 \cdot 51$ & $26 \cdot 15$ & $2 \cdot 8$ & 29 & 140 & 90 & 0 \\
\hline & 1870 & $55 \cdot 10$ & 33.94 & $3 \cdot 8$ & 27 & 140 & 95 & 9 \\
\hline 14 & 2520 & $78 \cdot 02$ & $32 \cdot 30$ & $2 \cdot 9$ & 32 & 160 & 90 & 0 \\
\hline & 2450 & $75 \cdot 30$ & $32 \cdot 54$ & 3.0 & 25 & 130 & 70 & 4 \\
\hline 15 & 1985 & $65 \cdot 77$ & $30 \cdot 18$ & $3 \cdot 9$ & 33 & 140 & 80 & 0 \\
\hline & 2360 & $65 \cdot 77$ & $35 \cdot 88$ & $3 \cdot 8$ & 32 & 140 & 80 & 5 \\
\hline 16 & 2615 & $63 \cdot 37$ & $41 \cdot 33$ & 3.0 & 28 & 140 & 90 & 0 \\
\hline & 1935 & $58 \cdot 28$ & $33 \cdot 20$ & $2 \cdot 4$ & 23 & 160 & 100 & 6 \\
\hline 17 & 2120 & $64 \cdot 52$ & $32 \cdot 86$ & $3 \cdot 4$ & 27 & 180 & 110 & 0 \\
\hline & 2530 & $63 \cdot 50$ & $39 \cdot 84$ & $3 \cdot 6$ & 28 & 145 & 90 & 6 \\
\hline 18 & 2434 & 92.08 & 26.43 & $3 \cdot 1$ & 36 & 140 & 85 & 0 \\
\hline & 3140 & $91 \cdot 85$ & $34 \cdot 19$ & 3.4 & 33 & 150 & 90 & 4 \\
\hline 19 & 2210 & $72 \cdot 58$ & 30.45 & $3 \cdot 1$ & 33 & 140 & 100 & 0 \\
\hline & 1840 & 70.07 & $26 \cdot 26$ & 3.6 & 27 & 160 & 100 & 2 \\
\hline 20 & 2770 & $86 \cdot 18$ & $32 \cdot 14$ & $3 \cdot 2$ & 31 & 140 & 90 & 0 \\
\hline & 3140 & 85.49 & 36.73 & $3 \cdot 7$ & 30 & 140 & 85 & 3 \\
\hline 21 & 2290 & $78 \cdot 69$ & $29 \cdot 10$ & $3 \cdot 7$ & 32 & 150 & 95 & 0 \\
\hline & 2495 & $78 \cdot 23$ & 31.89 & $3 \cdot 4$ & 32 & 140 & 80 & 5 \\
\hline 22 & 1460 & 48.99 & $29 \cdot 80$ & $3 \cdot 4$ & 29 & 170 & 110 & 0 \\
\hline & 1520 & $50 \cdot 11$ & $30 \cdot 33$ & $3 \cdot 4$ & 27 & 150 & 90 & 5 \\
\hline 23 & 2680 & $81 \cdot 19$ & 33.01 & $3 \cdot 1$ & 33 & 140 & 85 & 0 \\
\hline & 3448 & 82.55 & $41 \cdot 77$ & $4 \cdot 3$ & 28 & 110 & 75 & 2 \\
\hline 24 & 2740 & $71 \cdot 89$ & $38 \cdot 11$ & $2 \cdot 8$ & 33 & 140 & 90 & 0 \\
\hline & 2790 & $71 \cdot 21$ & $39 \cdot 18$ & $3 \cdot 7$ & 30 & 120 & 80 & 4 \\
\hline
\end{tabular}


bethanidine was employed in addition and in seven, $\alpha$-methyldopa was used; in one case both bethanidine and $\alpha$-methyldopa were used.

The potassium supplement was stopped after the initial exchangeable potassium estimation, and the subjects then received between 10 and $20 \mathrm{mg}$ amiloride/day in divided doses.

Twenty-four patients were studied on two occasions: before the onset of amiloride therapy and after a mean period of 4.8 months (range 2-9 months).

All of the patients were judged to be suffering from essential hypertension on the basis of clinical assessment, plasma electrolyte estimation before antihypertensive therapy, and other baseline investigations which were indicated clinically.

Subjects were not admitted to hospital, and took a normal diet for the total duration of the assessment.

Exchangeable potassium $\left(\mathrm{K}_{\mathrm{e}}\right)$ was measured with ${ }^{42} \mathrm{~K} ; 60 \mu \mathrm{Ci}$ was injected intravenously and the excretion of ${ }^{42} \mathrm{~K}$ measured in urine collected for the following $20 \mathrm{hr}$. Total exchangeable potassium was calculated from a urine sample collected after a further $1 \mathrm{hr}$ as follows:

$$
\mathrm{K}_{\mathrm{e}}=\frac{X-E}{C} \times m
$$

$C=$ concentration of tracer ${ }^{42} \mathrm{~K}$ in urine sample

$X=$ amount of tracer ${ }^{42} \mathrm{~K}$ administered

$E=$ amount of tracer ${ }^{42} \mathrm{~K}$ lost in 20 -hr urine

$m=$ concentration of stable potassium in urine sample used for calculation.

Plasma potassium and total dioxide estimations were performed using a Technicon SMA 6/60 flame photometer.

The blood pressure was measured at each outpatient attendance using a standard mercury sphygmomanometer. Pressure was recorded in the supine position to the nearest $5 \mathrm{mmHg}$. The patient was weighed at each attendance.

\section{Statistical analysis}

The significance of the difference between sample means was estimated by Student's $t$ test for the difference between the means of paired observations using a Hewlett-Pakard 9810A desk computer. Thus, each subject acted as his own control in this study.

\section{Results}

Total exchangeable potassium, plasma potassium, total $\mathrm{CO}_{2}$ and weight and blood pressure were estimated at the beginning of the study and after a mean period receiving amiloride therapy of 4.8 months (Table 1). The mean alterations in each parameter are summarized in Table 2, together with statistical significance. Significant elevations of exchangeable potassium, plasma potassium and the ratio of exchangeable potassium to body weight are demonstrated together with a significant fall in total $\mathrm{CO}_{2}$, weight and both systolic and diastolic blood pressures. The fall in systolic blood pressure level was statistically more significant than that of the diastolic pressure (Figs 1-5).

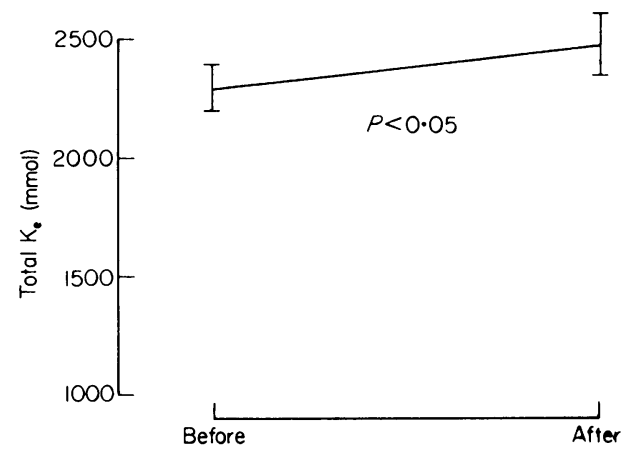

Fig. 1. Total exchangeable potassium before and after amiloride (mean duration 4.8 months).

TABLE 2. Total exchangeable potassium $\left(\mathrm{K}_{\mathrm{e}}\right)$, exchangeable potassium per kilogram body weight $\left(\mathrm{K}_{\mathrm{e}} / \mathrm{kg}\right)$, plasma potassium (mmol/l), total $\mathrm{CO}_{2}$, body weight and supine systolic and diastolic blood pressure, before and after amiloride therapy. The mean values are shown, with s.e. mean, s.d., and the statistical significance by paired $t$ test

\begin{tabular}{|c|c|c|c|c|c|c|}
\hline & \multicolumn{2}{|c|}{ Before } & \multicolumn{2}{|c|}{ After } & \multirow[b]{2}{*}{$t$} & \multirow[b]{2}{*}{$\boldsymbol{P}$} \\
\hline & Mean & s.e. mean & Mean & s.e. mean & & \\
\hline $\mathrm{K}_{\mathrm{e}}(\mathrm{mmol})$ & 2292 & $97 \cdot 3$ & 2466 & 121 & $2 \cdot 295$ & $<0.05$ \\
\hline $\mathrm{K}_{\mathrm{c}} / \mathrm{kg}(\mathrm{mmol} / \mathrm{kg})$ & $32 \cdot 17$ & 0.94 & 34.93 & $1 \cdot 1$ & $2 \cdot 79$ & $<0.02$ \\
\hline Plasma K+ (mmol/l) & $3 \cdot 15$ & $0 \cdot 07$ & $3 \cdot 62$ & $0 \cdot 1$ & $4 \cdot 27$ & $<0.001$ \\
\hline Total $\mathrm{CO}_{2}(\mathrm{mmol} / \mathrm{l})$ & $31 \cdot 5$ & 0.62 & $29 \cdot 1$ & 0.55 & $4 \cdot 48$ & $<0.001$ \\
\hline Weight $(\mathrm{kg})$ & $75 \cdot 51$ & $2 \cdot 26$ & $70 \cdot 35$ & $2 \cdot 28$ & $3 \cdot 818$ & $<0.001$ \\
\hline Systolic blood pressure $(\mathrm{mmHg})$ & $157 \cdot 1$ & $4 \cdot 7$ & $145 \cdot 6$ & $4 \cdot 0$ & $3 \cdot 25$ & $<0.01$ \\
\hline Diastolic blood pressure (mmHg) & $93 \cdot 3$ & $2 \cdot 4$ & $87 \cdot 3$ & $2 \cdot 0$ & $2 \cdot 60$ & $<0.02$ \\
\hline
\end{tabular}




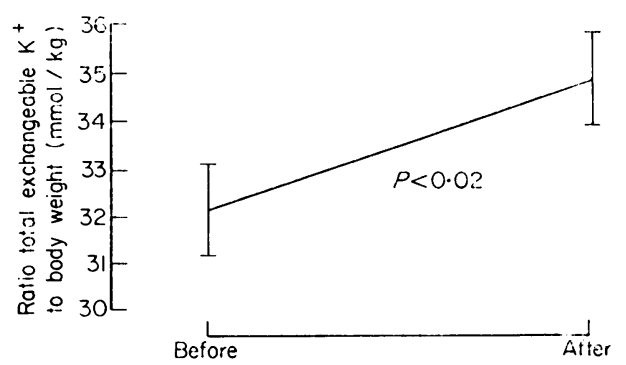

FIG. 2. Ratio of total exchangeable potassium (mmol) to body weight $(\mathrm{kg})$ before and after amiloride therapy (mean duration $4 \cdot 8$ months).

(Means and standard error of the mean are shown $P$ values derived by student's paired $t$ test.)

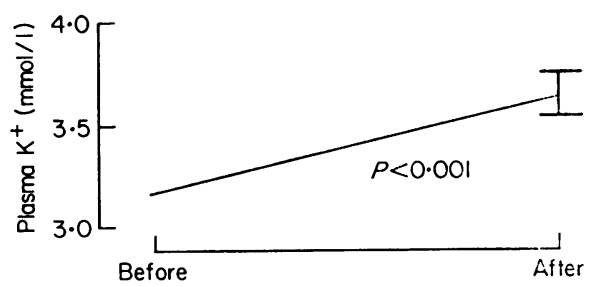

Fig. 3. Plasma potassium before and after amiloride therapy (mean $4 \cdot 8$ months).

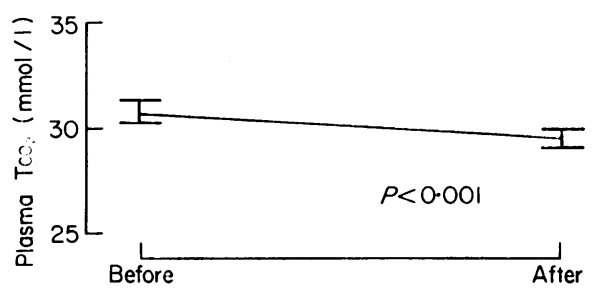

Fig. 4. Plasma $\mathrm{TCO}_{2}$ before and after amiloride.

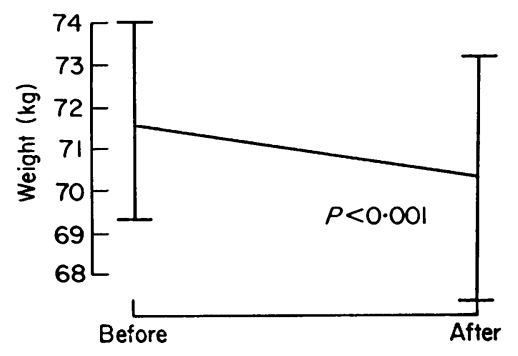

FIG. 5. Weight $(\mathrm{kg})$ before and after amiloride.

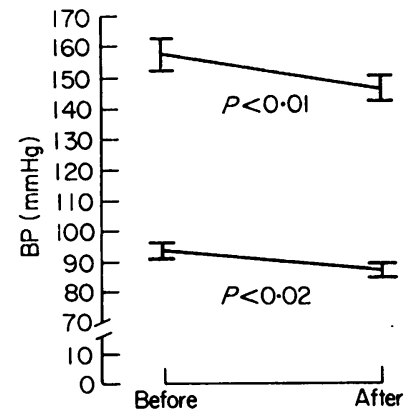

FIG. 6. Supine systolic and diastolic blood pressure of twenty-four patients before amiloride therapy and after a mean period of 4.8 months.

\section{Discussion}

Amiloride is an oral natriuretic and mild diuretic drug which appears to act primarily on the distal nephron.

It has a mild antihypertensive action in some patients (Bull and Laragh, 1968) It has been shown to elevate the plasma potassium when used alone (Surveyor and Saunders, 1968), or when it is substituted for oral potassium supplements in patientso who have become hypokalaemic whilst taking as thiazide diuretic along with potassium supplements (Antcliff et al., 1971).

On the other hand, a tablet containing amiloride $(5 \mathrm{mg})$ with hydrochlorthiazide $(50 \mathrm{mg})$ (Moduretic, Merck, Sharp \& Dohme), did not prevent hypokalaemia from resulting from its administration, nor restore to normal the plasma potassium level in patients already hypokalaemic (Antcliff et al., 1972).

Although hypokalaemia and mild metabolic alkalosis are common in hypertensive patients treated for prolonged periods with thiazide diuretics, symptoms are quite rare (Beevers et al., 1971), and the need to correct this has been questioned (Wilkinson et al., 1975; Healy et al., 1970). However, most clinicians are reluctant to allow patients who are already taking cardiac glycosides or who are in a group at increased risk of requiring them, to remain persistently hypokalaemic. The risk of a sudden potassium-losing state, such as diarrhoea or vomiting, has already been mentioned. It is therefore desirable to discover an agent which will effectively increase the plasma and whole body potassium if they become depleted.

Oral potassium was demonstrated, as a slowrelease potassium chloride, in a group of seven patients with hypertension treated with chlorthalidone, to replace the depleted $\mathrm{K}_{\mathrm{e}}$ and plasma potassium. However, twenty-four patients are presented, whose plasma potassium was diminished and in 
whom a raised $\mathrm{TCO}_{2}$ was recorded. These were measured on two separate occasions in spite of receiving at least $32 \mathrm{mmol} \mathrm{K}^{+} /$day and often much more.

These patients were drawn from a population of patients attending a Hypertension Clinic over a period of about 12 months, in whom significant hypokalaemia was quite common in spite of oral potassium supplements. As triamterene seems ineffective in replacing potassium, and spironolactone is often poorly tolerated, it seems important to assess the efficiency of amiloride in this situation. It has been demonstrated that amiloride in a dosage of $10-20 \mathrm{mg} /$ day causes a significant rise of exchangeable potassium, plasma potassium and $\mathrm{Ke}_{\mathrm{e}} / \mathrm{kg}$. There is also a significant fall in the $\mathbf{T C O}_{2}$ and weight and blood pressure. In view of the number of patients using the thiazide diuretics, the routine use of this agent would be prohibitively expensive. In most patients, the degree of depression of the plasma potassium that has been recorded in this group does not occur and hence this form of treatment is probably not necessary. It has been demonstrated, however, that in patients who develop and maintain a significant hypokalaemia it is effective in at least partly replacing the exchangeable potassium and elevating the plasma potassium into normal range. It is believed, therefore, that amiloride has a uesful part to play in this group of patients.

\section{References}

Anderson, J., Godfrey, B.E., Hill, D.M., Munro-Faure, A.D. \& SHELdon, J. (1971) A comparison of the effects of hydrochlorthiazide and of frusemide in the treatment of hypertensive patients. Quarterly Journal of Medicine, 40, 160,541 .
Antcliff, A.C., Beevers, D.G., Hamilton, M. \& Harpur, J.E. (1971) The use of amiloride hydrochloride in the correction of hypokalaemic alkalosis induced by diuretics. Postgraduate Medical Journal, 47, 644.

Antcliff, A.C., Beevers, D.G., Hamilton, M. \& Harpur, J.E. (1972) Amiloride hydrochloride combined with hydrochlorthiazide in the control of hypertension and plasma potassium levels. British Journal of Clinical Practice, 26, 413.

Beevers, D.G., Hamilton, M., Harpur, J.E. (1971) The long-term treatment of hypertension with thiazide diuretics. Postgraduate Medical Journal, 47, 639.

Bull, M.B. \& LaRAGH, J.H. (1968) Amiloride, a potassiumsparing natriuretic agent. Circulation, 37, 45.

Gifford, R.W., Mattox, V.R., ORvis, A.L., Sones, D.A. \& Rosevear, J.W. (1961) Effect of thiazide diuretics on plasma volume, body electrolytes and excretion of aldosterone in hypertension. Circulation, 24, 1197.

Graybiel, A.L. \& Sode, J. (1971) Diuretics, potassium depletion and carbohydrate intolerance. Lancet, ii, 265.

Healy, J.J., McKenna, T.J., Canning, B.St.J., O'Brien, T.G., Duffy, G.J. \& Muldowney, F.P. (1970) Body composition changes in hypertensive subjects on long-term oral diuretic therapy. British Medical Journal, 1, 716.

Leemhuis, M.P., van Damme, K.J. \& Stuyvenberg, A. (1976) Effects of chlorthalidone on serum and total body potassium in hypertensive patients. Acta medica scandinavica, 200, 37.

Maronde, R.F., Milgram, M. \& Dickey, J.M. (1969) Potassium loss with thiazide therapy. American Heart Journal, 78, 1, 16.

McKenna, T.J., Donohoe, J.F., Brien, T.G., Healy, J.J., CANNING, B.St.J. \& Muldowney, F.P. (1971) Potassiumsparing agents during diuretic therapy in hypertension. British Medical Journal, 2, 739.

Surveyor, I. \& SAUnders, R.A. (1968) Amiloride and plasma potassium. Lancet, ii, 516.

Talso, P.J. \& Carballo, A.J. (1960) Effects of benzothiazines on serum and body electrolytes. Annals of New York Academy of Sciences, 88, 882.

Wilkinson, P.R., Issler, H., Hesp, R. \& Raferty, E.B. (1975) Total body and serum potassium during prolonged thiazide therapy for essential hypertension. Lancet, ii, 759. 